\title{
TREATMENT OF UNCERTAINTY THROUGH THE INTERVAL SMART/SWING WEIGHTING METHOD: A CASE STUDY
}

\author{
Luiz Flávio Autran Monteiro Gomes ${ }^{1 *}$, Luis Alberto Duncan Rangel ${ }^{2}$ \\ and Miguel da Rocha Leal Junior ${ }^{3}$
}

Received December 30, 2009 / Accepted January 17, 2011

\begin{abstract}
An increasingly competitive market means that many decisions must be taken, quickly and with precision, in complex, high risk scenarios. This combination of factors makes it necessary to use decision aiding methods which provide a means of dealing with uncertainty in the judgement of the alternatives. This work presents the use of the MAUT method, combined with the INTERVAL SMART/SWING WEIGHTING method. Although multicriteria decision aiding was not conceived specifically for tackling uncertainty, the combined use of MAUT and the INTERVAL SMART/SWING WEIGHTING method allows approaching decision problems under uncertainty. The main concepts which are involved in these two methods are described and their joint application to the case study concerning the selection of a printing service supplier is presented. The case study makes use of the WINPRE software as a support tool for the calculation of dominance. It is then concluded that the proposed approach can be applied to decision making problems under uncertainty.
\end{abstract}

Keywords: multicriteria decision aiding, uncertainty, INTERVAL SMART/SWING WEIGHTING method.

\section{INTRODUCTION}

Currently, the worldwide scenario is principally characterised by constant changes and the need to adjust a company to the market in an agile and precise manner. Competition in all areas means that decision makers increasingly must make important decisions for complex problems generally in a short time with incomplete information and with significant impacts as a consequence of the decision. This scenario increases the risk of error, and, consequently, increases the cost often as a result of the need to revise the choice or to live with it.

\footnotetext{
*Corresponding author

${ }^{1}$ Ibmec/RJ, Av. Presidente Wilson, 118, Sala 1110, Centro, 20030-020, Rio de Janeiro, RJ, Brazil.

E-mail: autran@ibmecrj.br

2 Escola de Engenharia Industrial Metalúrgica de Volta Redonda - UFF, Av. dos Trabalhadores 420, Vila Santa Cecília, 27255-125, Volta Redonda, RJ, Brazil. E-mail: duncan@metal.eeimvr.uff.br

${ }^{3}$ Wella/Tecnologia da Informação, Avenida das Américas, 700, Bloco 5, Sala 112, Barra da Tijuca, 22640-100, Rio de Janeiro, RJ, Brazil. E-mail: leal.mr@pg.com
} 
In the 1990s the outsourcing of operational services to specialised companies was the solution found for many companies to cut costs through large contracts and economies of scale, in this way maintaining the focus of the company on the business. The search for partners who could supply a quality service and the capillarity that a multinational requires, with long term contracts, has made the choice complex with important impacts and consequences.

In order to solve one of the management problems in IT, namely its printing service, the company, here called W-Cosmetic, opted for the outsourcing of this service, and decided to choose the supplier using the decision aiding methods known as MAUT (Multiattribute Utility Theory), published by Keeney \& Raiffa (1976); and INTERVAL SMART/SWING WEIGHTING, published by Mustajoki, Hamalainen \& Salo (2005), developed to deal with uncertainty in the definition of the values of the alternatives and the weights of the attributes. The software WINPRE (2009), which is available for academic use on an Internet page, will be used to determine dominance.

The printing service includes numerous operational activities, consequently generating nonproductive work, as is called work which is not directly linked to the company strategy. The following could be cited as examples: Management of Assets and Contracts; Management of Hardware Problems and Support Calls; and Management of Costs by Department. Currently, the company has a plant of 25 printers of its own, seven of them being dot matrix and the others multifunctional laser machines, installed in the cities of Rio de Janeiro, Duque de Caxias, São Paulo, Guarulhos, and Salvador. The management of maintenance, backup parts and consumables, as well as the management of support calls are the responsibility of W-Cosmetic. Various companies are contracted to carry out the maintenance of these printers, depending on the location where they are installed. There is no satisfactory control of the volume printed by department, with some departments which spend less receiving greater costs than they should due to sharing the costs of other departments. The annual cost of the current solution was estimated at 500,000 reais. The plant installed is already obsolete in relation to the current printing needs as regards volume, confidential printing resources, A3 coloured printing, A3 black and white copies and scanner.

For all the problems described, W-Cosmetic decided to open a project of outsourcing the printing service with the following as the main objectives: $i$ ) To reduce printing costs; ii) To meet the new needs of printing volume resources, paper size, confidential printing, printing restrictions as well as the copy, fax and scanner functions; iii) To permit the accounting of printing per cost centre; $i v$ ) To guarantee the operational continuity of the printers and multifunctional printers; $v$ ) To reduce the operational load of the IT staff as regards the management and maintenance of equipment, requests for consumables and maintenance of backups.

\section{METHODOLOGY}

\subsection{The MAUT method}

Multiattribute Utility Theory was introduced by Keeney \& Raiffa (1976) as an extension of Utility Theory largely developed by Fishburn (1970). It is concerned with the construction of 
a mathematical function called "Multiattribute Utility Function", which presupposes that it is possible to give a value to every attribute. Many pieces of research have been written recently which work with utility theory (Gomes \& Rangel, 2009; Meirelles \& Gomes, 2009; Rangel \& Gomes, 2009).

Multiattribute Utility Theory does not accept "Incomparability", in other words, it assumes that all the alternatives can be compared according to the defined attributes. The decision maker must choose one and only one from among the statements below when comparing two alternatives:

- "a" is preferable to " $\mathrm{b} " \leftrightarrow \mathrm{aPb}$;

- "b" is preferable to "a" $\leftrightarrow \mathrm{bPa}$;

- "a" is indifferent to "b" $\leftrightarrow$ aIb $\vee$ bIa.

Table 1 shows the preferences of the decision agent according to Roy and Bouyssou (1993) for the MAUT method.

Table 1 - The preferences of the decision agent according to Roy and Bouyssou (1993).

\begin{tabular}{|l|l|l|}
\hline \multicolumn{1}{|c|}{ Situation } & \multicolumn{1}{|c|}{ Definition } & \multicolumn{1}{c|}{ Binary relation } \\
\hline Indifference & $\begin{array}{l}\text { There are strong arguments which show that } \\
\text { two alternatives are equivalent. }\end{array}$ & $\begin{array}{l}\text { I: Symmetrical } \\
\text { and reflexive }\end{array}$ \\
\hline $\begin{array}{l}\text { Strict } \\
\text { preference }\end{array}$ & $\begin{array}{l}\text { There are strong arguments which show that } \\
\text { one alternative is better between the two. }\end{array}$ & $\begin{array}{l}\text { P: Asymmetrical } \\
\text { and irreflexive }\end{array}$ \\
\hline
\end{tabular}

Transitivity is present in this method in the following way: if alternative "a" is preferable to " $b$ "; and alternative " $b$ " is preferable to " $c$ ", then " $a$ " is preferable to "c" (preference transitivity); and if alternative "a" is indifferent to " $b$ "; and alternative " $b$ " is indifferent to "c", then "a" is indifferent to "c" (indifference transitivity).

When a problem is well structured, half of the problem is already solved (Belton \& Stewart, 2002). This structuring involves identifying key questions, objectives, the people involved, actions, alternatives, criteria, and weights which will make evaluations and discussions possible (Rosenhead \& Mingers, 2008).

The key questions can be identified through various methods such as, for example, "brainstorming" where the participants openly and informally discuss among themselves making individual notes. In a second stage, each participant communicates their ideas stimulating new discussions, and finally, the ideas are structured. The use of software can help in the structuring of MultiCriteria Decision Aiding (MCDA) problems, although, depending on the participants, it can also discourage participation (Belton \& Stewart, 2002).

The identification of the alternatives consists of defining which options exist as solutions for the question raised, and occurs interactively with the criteria, as the evaluation of one can lead to the 
re-evaluation of the other (Gomes, Araya \& Carignano, 2004). Often it is necessary to reduce the number of alternatives defining a limiting parameter with the purpose of making the process of comparison simpler. Bogetoft \& Pruzan (1991) describe it as a search and learning process concerning the alternatives which must be considered and their relation with the objectives of the question.

Defining the criteria is to choose the relevant points which can be used to compare the alternatives, establishing relations of preference between them (Roy, 1985). A criterion, as well as the form of evaluating an alternative according to this criterion must be understood and accepted by all those involved in the decision making process. The lack of a common understanding can have serious consequences including leading to the choice of an alternative that is not the best. The quality of the data collected, the definition and the clear structuring of the problem have a direct influence on the definition of the criteria. Roy (1985) also considers that the culture of those involved in the decision making process contributes to the definition of the criteria and to the importance given to each of them in the solution of the problem.

The following properties are desirable for a group of attributes according to Keeney \& Raiffa (1976):

i. Coverage: a family of attributes can be considered complete when they reflect all the objectives raised concerning the problem. If this does not occur, important aspects of the problem may not be considered, and, therefore, the decision assumes a greater risk of error;

ii. Operationality: the criteria must be well-defined and viable for working with and scoring, making it possible for the decision maker to understand the implications of the alternatives, as well as sharing them with the others involved;

iii. Decomposability: this consists of being able to evaluate an alternative according to a determined criterion, independently of the other criteria. On the other hand, for problems involving many attributes, it is fundamental that these criteria can be divided into groups so as to simplify the evaluation of the alternatives;

iv. Non-duplication: each criterion must have a unique significance, without duplication with the others, in this way avoiding the attributed values being counted twice. If two criteria are duplicated, the evaluation of an alternative according to one of these criteria, necessarily leads to the same evaluation according to the other criterion. This alters the final evaluation, having a direct influence on the decision;

v. Minimum Size: it is desirable to keep the number of attributes as small as possible, as the difficulty in quantifying attributes grows as the number of attributes is increased. On the other hand, it is important to maintain the property "Completeness". A balance needs to be maintained between these two properties (Belton \& Stewart, 2002), so as to guarantee that all the objectives are being considered. The number of attributes can be reduced by combining them when they are evaluated as a set, or eliminated when there is no distinction between the alternatives in relation to it. 
The determination of the weight is an inter-criteria evaluation, in other words, it is the importance of one criterion in relation to another (trade-off values). These weights define marginal rates of substitution, which make it possible to compensate the diminishing of the performance of one criterion with the improvement of another criterion. It is important that those involved in the decision making process understand and accept the values defined here (Gomes, Araya \& Carignano, 2004).

Once the scoring of each alternative has been calculated, as well as the marginal rates of substitution for each criterion, the aggregate value can be calculated through the linear additive value function given by the expression (1):

$$
V(a)=\sum_{j=1}^{n} W_{j} V_{j}(a)
$$

where, $W_{j}$ is the weight of the criterion $j$, and $V_{j}(a)$ is the performance of the alternative in relation to the criterion $j$, resulting in the aggregate value of the alternative $a$. This must be done for each of the alternatives, and, at the end, they are ranked from highest score (best alternative) to the lowest score (worst alternative).

In order to use this function it is necessary for all criteria to be mutually independent, in terms of preference, in other words, that the evaluation of one alternative in relation to one criterion does not have any influence from another criterion. It is said that the criteria are independent among themselves, if any subset of criteria is independent regarding the preferences in relation to its complementary subset. If there is not independence between the criteria, it is recommended that the family of criteria is redefined through the grouping of dependent criteria, or even the redefinition of the criteria (Clemen \& Reilly, 2001).

During the evaluation the concept of dominance can still be used. This concept is based on the definition that if alternative "a" is as good as alternative " $b$ " for all the criteria and has Strict Preference for at least one of the criteria, then it is said that "a" dominates " $b$ ". The set of alternatives not dominated is called the "Pareto Optimal Set". The use of this concept is important to restrict the alternatives and facilitate the decision (Belton \& Stewart, 2002).

As there is subjectivity in the definition of the values of the attributes and weights, a sensitivity analysis becomes necessary. Bana \& Costa (1990) comments on the need to make sensitivity analyses questioning the results of the models, seeking to give greater consistency to the final results. According to Belton \& Stewart (2002), after obtaining the results, it is necessary to check the validity, in other words, to check if they are solid or sensitive to the change in the values attributed to the attributes and weights. The sensitivity analysis normally involves the variation of one parameter keeping the others unaltered. This type of analysis called unidimensional does not supply a more detailed evaluation of the model, as it does not allow for the simultaneous and interactive analysis of the weights. Keeney (1982) presents some difficulties in the execution of the phases of the decision making process:

i. the presence of various decision makers with different profiles; 
ii. risk and uncertainty, as well as the attitude of the decision makers in the face of these situations;

iii. e presence of intangible factors which contribute to increasing the sensation of risk and uncertainty of those involved in the decision process;

iv. resence of different groups which can be affected by the decision, also involving policy and power considerations;

v. he existence of multiple criteria, as well as the evaluation of independence between them;

vi. the difficulty of finding alternatives which satisfy these criteria;

vii. a long term horizon.

The definition of the weights is a fundamental part of MAUT, and it needs special attention from the decision makers. Some techniques have been developed to facilitate this decision so that the weights defined represent the preferences given by the decision makers.

Some more sophisticated methods are presented as follows:

\section{- SMART (Simple Attribute Rating Technique)}

Published by Edwards in 1971 (Edwards, 1971), this technique carries out the definition of the weights in two stages: firstly, all the attributes are ranked in order of importance, considering their best performance. In the second stage, the least important attribute is given the value 10 , the other attributes are then evaluated with more than 10 points according to the degree of importance in relation to the least important attribute, all being normalised to a total sum of 1 .

\section{- SWING WEIGHTING}

This method was published in 1986 by von Winterfield and Edwards (Von Winterfeld \& Edwards, 1986), and consists of the idealisation of a hypothetical alternative where the attributes are taken to their worst level, and which will be used as a comparison (benchmark).

At a second stage, the attributes are classified in order of importance, responding to the following question: which are the attributes such that, by changing from the worst to the best levels, the most positive impacts on the hypothetical alternative are caused? This is carried out for each attribute until all are ranked. The value 0 is attributed to the benchmark alternative. The most important attribute is attributed the value 100. The other attributes are valued through a direct comparison, which can be thought of as a value, or as a percentage in relation to the change of the attribute from its worst to its best level. Finally, the weights are normalised to 1.

\subsection{The SMART/SWING WEIGHTING Method - Judgements by Intervals}

In a process of multicriteria decision analysis, uncertainty is always present, principally as regards the scoring of the alternatives in relation to the criteria, and the definition of the weights of each criterion. 
The uncertainty can be caused by the company culture, by the individual experience of each participant of the decision making process, by personal priority or that of the respective area, or even due to the lack of complete information. The highly competitive market and the consequent need to launch new products and make important decisions in a short time can bring significant impacts in financial terms, including negative impacts. Decisions must be made quickly and with incomplete information.

Judgements using intervals is one of the suitable ways of dealing with imprecision (Weber, 1987), substituting a single score by an interval which identifies the possible points that a determined alternative or criterion may assume.

The SMART and SWING WEIGHTING methods are much used in multicriteria decisions, and the use of judgements by intervals in these methods is an important tool to work with imprecision.

While the least important or most important attribute is commonly chosen as the reference attribute in the application of the SMART and SWING WEIGHTING methods, when making judgements by intervals, the reference attribute can be any one. In this way, an attribute which is easy to measure, which is best understood by all and score with precision can be chosen.

This attribute is given a single score, in other words, it is not judged by intervals of points. From this, the other attributes are scored in intervals which represent the possible variation that an attribute can have in relation to the reference attribute. The number of judgements will be calculated by the expression (2):

$$
2 \cdot(n-1)
$$

that is, each attribute will be judged twice in relation to the reference attribute so that maximum and minimum values be defined. Different methods of scoring can arrive at different results (Weber \& Borcherding, 1993; Poyhonen \& Hamalainen, 2001).

When an interval of values is defined for a determined alternative in relation to a determined attribute, only this alternative is affected by this variation of points, that is, the judgement of one alternative is independent of the judgement of another alternative in relation to the attributes. On the other hand, the judgement of an attribute is defined through the comparison of this with the other attributes. Differently from the judgement of the alternative, a variation in the weight of an attribute affects all the alternatives in a linear fashion (Keeney \& Raiffa, 1976). In this way, the calculation of dominance uses linear programming to model uncertainties and proceeds towards the maximum and minimum aggregate values. This is accomplished by using the concept of feasible region for the weights, which, by definition, is the region that meets the limits of the weights. It is not the objective of this article to examine linear programming in depth, but solely for better understanding, the following example is presented:

Supposing a situation with 3 attributes: $W_{a}$ [reference attribute $\left.=1\right] ; W_{b}[0.5 ; 2] ; W_{c}[1 ; 3]$. The limits of the relation between the attributes are calculated by the equation (3):

$$
\frac{r e f}{\max _{i}} \leq \frac{W_{r e f}}{W_{i}} \leq \frac{r e f}{\min _{i}}
$$


with $W_{\text {ref }}$ being the score given for the reference attribute, $\max _{i}$ the maximum limit of the nonreference attribute, and $\min _{i}$ the minimum limit of the non-reference attribute.

Substituting the values of the intervals in the equation (3), there is:

$$
\frac{1}{2} \leq \frac{W_{a}}{W_{b}} \leq 2 \quad \frac{1}{3} \leq \frac{W_{a}}{W_{c}} \leq 1 \quad \frac{1}{6} \leq \frac{W_{b}}{W_{c}} \leq 2 .
$$

As there are three variables, it is represented graphically as a polyhedron with the vertices in 1 , as in the INTERVAL SMART/SWING method the weights are normalised to 1. Signalling the limits in the plane formed by the three vertices and tracing the vectors from each vertex to the limits on the opposite side, the feasible region " $\mathrm{S}$ " is reached at the intersection of the areas as shown in Figure 1:

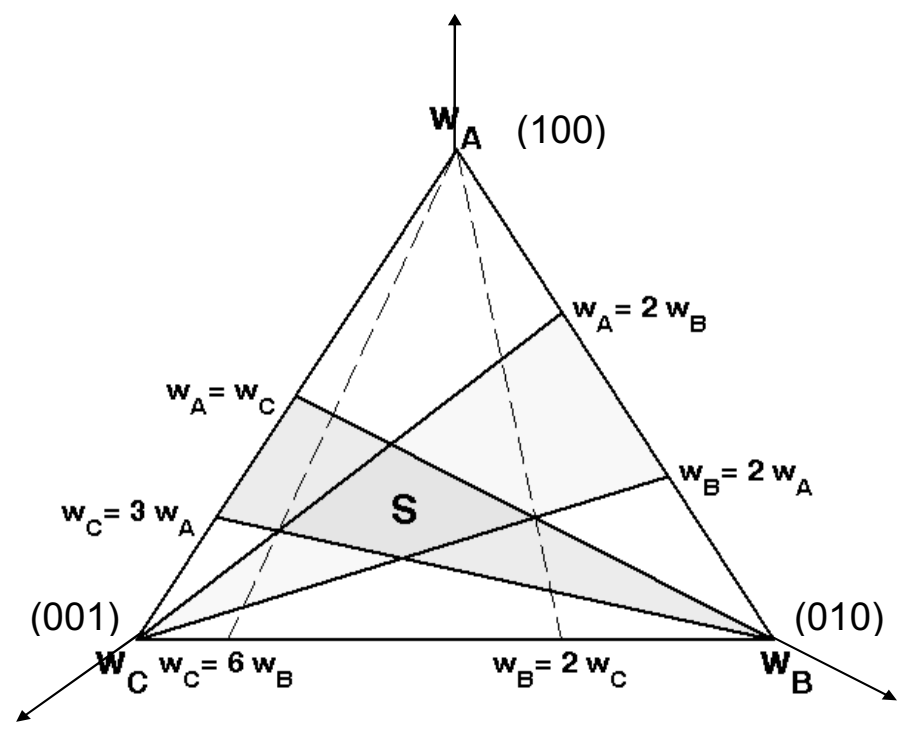

Figure 1 - Example of feasible region.

The aggregate values are calculated considering the feasible region, in accordance with the equations (4) and (5), minimum aggregate value and maximum aggregate value respectively:

$$
\begin{aligned}
& \underline{V}(a)=\min _{w \in S} \sum_{j=1}^{n} W_{j} V_{j}\left(a_{j}\right) \\
& \bar{V}(a)=\max _{w \in S} \sum_{j=1}^{n} W_{j} V_{j}\left(a_{j}\right)
\end{aligned}
$$

where, $W_{j}$ is the weight and $V_{j}\left(a_{j}\right)$ is the scoring of the alternative for each of the criteria, resulting in the maximum and minimum aggregated values of the alternative "a".

The solution of the problem consists of determining which alternative dominates all the others. It is said that alternative " $a$ " dominates alternative " $b$ ", if the aggregated value of " $a$ " is greater 
than the aggregated value of "b", for any combination within the feasible region. The mathematical representation is given by the equation (6):

$$
\min _{w \in S} \sum_{j=1}^{n} W_{j}\left(\underline{V}_{j}\left(a_{j}\right)-\bar{V}_{j}\left(b_{j}\right)\right) \geq 0
$$

that is, if the aggregate value of alternative "a" calculated by its respective minimum values is greater than the aggregate value of alternative " $b$ " calculated by its respective maximum values, for any combination inside the feasible region, then the expression will have a result greater than zero, meaning that alternative "a" dominates alternative "b".

The choice of the reference attribute is the first step in developing the method, and is fundamental in order to obtain the dominant alternative. According to Mutajoki, Hamalainen \& Salo (2005), the recommended sequence for the choice of the reference attribute is:

i. If it is possible to identify the attribute with the least imprecision, then this must be chosen as the reference attribute;

ii. If the imprecision cannot be differentiated among the attributes, then the most important attribute must be chosen.

The identification of the most precise or most important attribute points to the need for a wideranging discussion among the participants in the decision making process during the criteria defining phase, with the objective of seeking alignment in the understanding of what each of them signifies.

The intervals represent the imprecision in the judgement of an alternative in relation to each attribute, or the imprecision in the definition of the weight of each attribute. Each of these judgements can have different levels of uncertainty from the judge, which consequently defines different intervals. The larger the interval, the greater the imprecision and consequently, the greater the number of non-dominated alternatives.

Even if the best choice for the reference attribute has been made, it is still possible that not all of the alternatives are dominated. In this case, it is necessary to use other decision rules to be able to rank them (Salo \& Hamalainen, 2001). Some techniques can be applied to reduce the number of non-dominated alternatives:

i. Pre-Analysis of Alternatives: To define the minimum values for the main attributes, and eliminate the alternatives which do not accord with these values. This stage is very useful in the evaluation of information technology services, as normally there are a large number of suppliers of these services, though some of them are found to be without the structure to carry them out;

ii. Variation of the Intervals: after the first result of dominance, the decision maker can carry out a 'what-if' analysis, varying the intervals until a single dominant alternative is obtained. This can be done by a more detailed study of each maximum and minimum 
value attributed, seeking to reduce the imprecision, or even to correct values attributed to the alternatives and to the attributes.

After a single dominant alternative has been identified, it is good to check the attributed intervals to ensure that they represent the imprecision of each attribute and/or alternative. This can be done, for example, using one of the methods below:

i. Centralization of the Minimum and Maximum Aggregate Values: after calculating the maximum and minimum aggregate values, the central value of each alternative can be calculated, adding these aggregate values and dividing by two. In this way, all the alternatives will have a single aggregate value (central), and the dominant value will be that which has the highest value;

ii. Minimum or Maximum Aggregate Value: the ranking of the alternatives can be made by choosing the maximum or minimum value as the reference. The dominant alternative will be that which has the highest value in the reference chosen.

The use of the MAUT and INTERVAL SMART/SWING WEIGHTING methods is therefore efficient in dealing with uncertainty in situations of medium and high risk, permitting a quick and precise decision even with incomplete information. However, all due care must be taken in the evaluation of the alternatives, weights and choice of the reference attribute.

\section{CASE STUDY}

\subsection{Evaluation criteria}

A series of interviews with managers of the company led to identifying the alternatives as well as evaluation criteria for the case study. The same mangers would be later interviewing aiming to provide judgments on the performance of each alternative with respect to criteria.

Figure 2 presents, through a "Value Tree", the criteria which shall be used in the evaluation of the alternatives.

It should be observed that this representation of the Value Tree is not the same as used in the AHP method (Saaty, 1994). The criteria are described as follows:

i. Service Level Agreement: this measures the time taken to resolve a problem from receiving the call, considering Customer Service $24 \times 7$ ( 7 days a week, 24 hours a day). The less time taken, the greater the score in this requirement. Time periods above 24 hours for Duque de Caxias or Guarulhos should be scored zero, as these are the most important distribution centres. This is defined as a precise criterion because its values are welldefined and clear to the decision maker;

ii. Service Capillarity: this evaluates which locations are serviced by the company itself, and which are serviced by sub-contracted companies. It is understood that the greater 


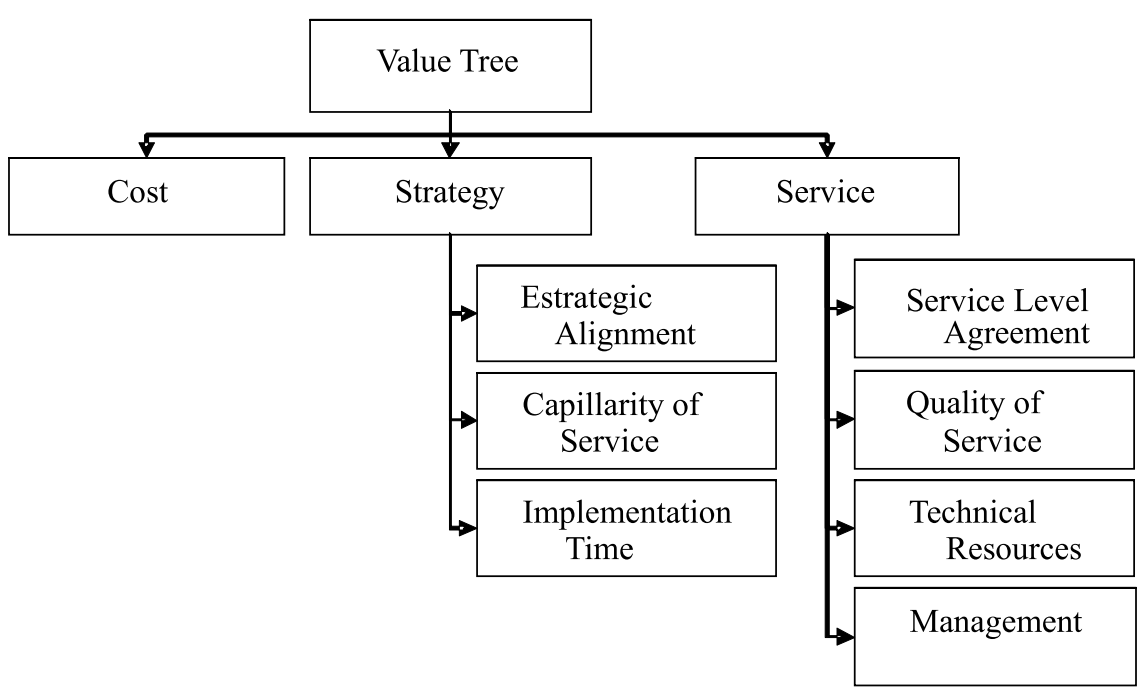

Figure 2 - Value Tree.

the number of locations that are serviced directly, the better the quality of service and technical empowerment. Companies which do not provide service directly in the São Paulo area should be scored zero. It is defined as an imprecise criterion as there is some disagreement over the true importance which should be attributed to this criterion;

iii. Technical resources: this evaluates the printing, copy, fax and scanner resources available. The greater the resources available within those described in the specifications, the higher the score. It is defined as a precise criterion, as the main companies have all or almost all of the resources;

iv. Cost: this evaluates the annual cost of each solution. In the first phase, it is important that the alignment of the proposals with the specification is carried out well in order to avoid large differences due to the lack of a clear understanding. Following the recommendation for the choice of a reference attribute according to Mutajoki, Hamalainen \& Salo (2005), this attribute was identified as the attribute with the greatest degree of precision in the definition of the corresponding weight. The attribute will be given the value one and will be the reference attribute in the evaluation of the other attributes. It is common to find cost to be the most important attribute, but in this case, it was not very clear for the decision makers. If it were, one would have the ideal situation where the reference attribute is at the same time the most precise and the most important;

v. Strategic Alignment: this evaluates the capacity of the company to participate in a global alignment, establishing a standard for Latin America. It evaluates the possibilities of servicing companies in the same group beyond Brazil: Mexico, Argentina, Chile, Venezuela and Colombia. It is defined as an imprecise criterion, as there is not sufficient information defining how the service will be effected; 
vi. Management (abbreviated as 'mgt'): this evaluates how much operational work will be taken away from the contracting company. It also evaluates the capacity to issue accompanying management reports which will make it possible to carry out cost analysis by cost centres with the aim of reducing the volume of printing. The use of a system via WEB in which it is possible to consult and carry out these evaluations is considered as a positive point. This is defined as an imprecise criterion due to the subjectivity of the evaluation;

vii. Quality of Service: this is evaluated based on a questionnaire sent to three clients indicated by each of the competing companies. The objective is to check if even a client indicated by the company would not evaluate the service provider well;

viii. Time of Implementation: this is the time taken to implement the project, counting from the signing of the contract. The maximum acceptable period is two months.

\subsection{Results}

\subsubsection{Prior analysis}

A first analysis was performed to check whether all of the suppliers were within the maximum implementation period. Two suppliers were eliminated as shown in Table 2, as the period was above 2 months, the maximum period defined by the company. In this research, the suppliers are the alternatives considered in the evaluation.

Table 2 - Evaluation of the alternatives according to the minimum criteria.

\begin{tabular}{|c|c|}
\hline Alternatives & $\begin{array}{c}\text { Period of } \\
\text { implementation } \\
\text { (months) }\end{array}$ \\
\hline Alternative 1 & 1.5 \\
Alternative 2 & 2.0 \\
Alternative 3 & 2.0 \\
Alternative 4 & 3.0 \\
Alternative 5 & 2.0 \\
Alternative 6 & 1.0 \\
Alternative 7 & 3.0 \\
Alternative 8 & 1.5 \\
Alternative 9 & 2.0 \\
Alternative 10 & 2.0 \\
\hline
\end{tabular}

\subsubsection{Dominance analysis}

The WINPRE software (2009), which is available for academic use, was used to determine dominance. The suppliers 4 and 7 were not considered as they had been eliminated in the previous stage. In this way, the research was carried out considering the remaining eight suppliers, $A_{1}, A_{2}, A_{3}, A_{5}, A_{6}, A_{8}, A_{9}, A_{10}$. 
Figure 3 presents the "Value Tree" captured through the WINPRE system (2009), with the evaluation criteria and the alternatives.

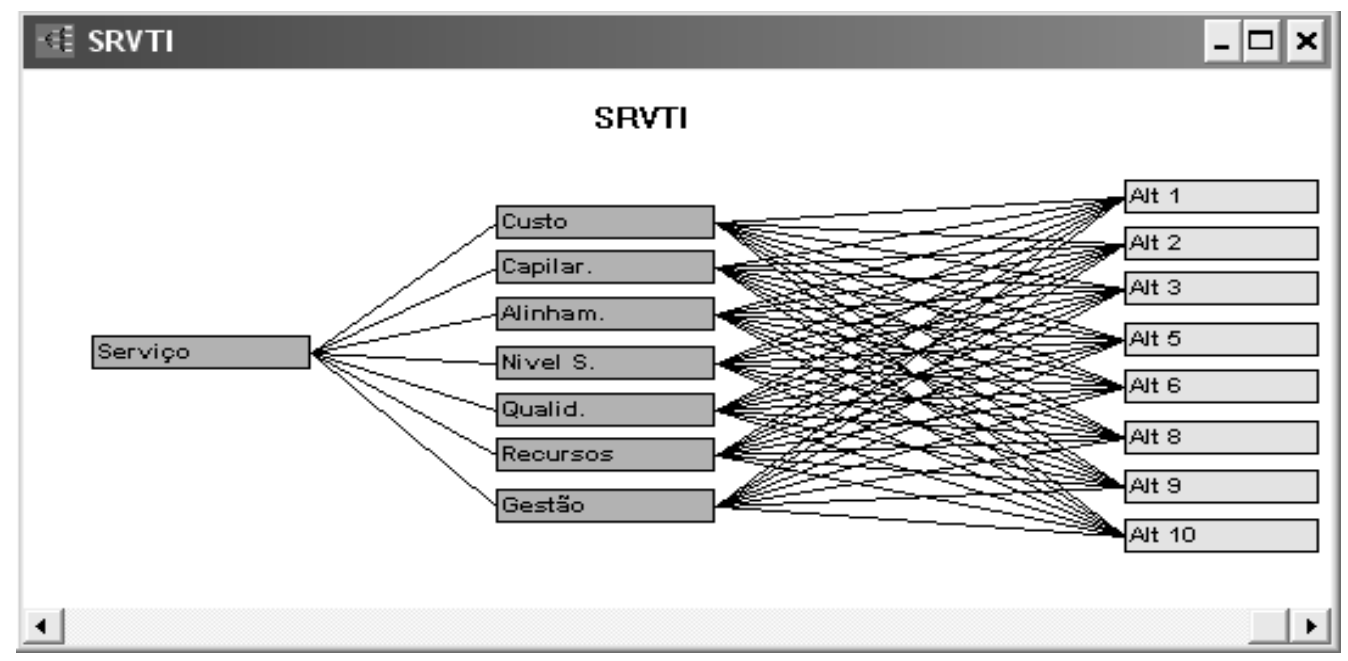

Figure 3 - Value Tree captured by the WINPRE software.

The evaluation of the alternatives according to the criteria established in the analysis is presented in the evaluation matrix in Table 3. The information in this table contains some imprecision and decision makers considered that there was no time to refine them such that imprecision could be removed. In order to tackle this imprecision it was decided that the INTERVAL SMART/SWING WEIGHTING method should be used. The use of this method implies that, for precise data, a single value should be set as to represent them. For imprecise data, on the other hand, the ranges of intervals should vary with the size of the perceived imprecision: the larger this perceived imprecision, the larger that range. This allowed treating the imprecision embedded in Table 3.

As mentioned in Section 3.1, alternatives, criteria and the performance of each alternative with respect to criteria were obtained through a series of interviews with managers of the company. In this case study each alternative can not be clearly identified in this article due to the fact the potential suppliers did not authorize the disclosure of their names.

Considering Table 3 with the responses to each of the alternatives, already discounting alternatives 4 and 7 eliminated in the previous phase (Table 2), it is possible to create Table 4 where the minimum and maximum values for the alternatives in relation to each attribute are presented.

Figure 4 presents the minimum and maximum values of each alternative in relation to the criterion "Management", inserted in the WINPRE software (2009).

Calculation of the intervals of the weights in relation to the reference attribute.

Figure 5 presents the maximum and minimum values attributed to each of the criteria, in relation to the attribute reference "Cost". 
Table 3 - Evaluation of the alternatives according to the established criteria.

\begin{tabular}{|c|c|c|c|c|c|c|c|}
\hline \multirow{2}{*}{ Alternatives } & \multicolumn{7}{|c|}{ Criteria } \\
\cline { 2 - 9 } & $\begin{array}{c}\text { Anual } \\
\text { cost }\end{array}$ & Capillarity & $\begin{array}{c}\text { Strategic } \\
\text { alignment }\end{array}$ & SLA & $\begin{array}{c}\text { Quality of } \\
\text { service }\end{array}$ & $\begin{array}{c}\text { Technical } \\
\text { resources }\end{array}$ & Mgt \\
\hline Alt. 1 & 400.000 & Brazil & Brazil & $6 \mathrm{~h}$ & 7.7 & All & V. Good \\
\hline Alt. 2 & 450.000 & RJ and SP & L.A. & $4 \mathrm{~h}$ & 6.3 & All & Good \\
\hline Alt. 3 & 420.000 & RJ and SP & $\begin{array}{c}\text { L.A. except } \\
\text { for Colombia }\end{array}$ & $8 \mathrm{~h}$ & 6.0 & All & V. Good \\
\hline Alt. 5 & 390.000 & Brazil & Brazil & $6 \mathrm{~h}$ & 6.3 & $\begin{array}{c}\text { Without color } \\
\text { scanner copy }\end{array}$ & Regular \\
\hline Alt. 6 & 425.000 & Brazil & Brazil & $24 \mathrm{~h}$ & 6.0 & All & Good \\
\hline Alt. 8 & 415.000 & RJ and SP & $\begin{array}{c}\text { L.A. except } \\
\text { for Colombia } \\
\text { and Venezuela }\end{array}$ & $48 \mathrm{~h}$ & 8.3 & Without & confidential \\
printing & V. Good \\
\hline Alt. 9 & 430.000 & RJ and SP & $\begin{array}{c}\text { L.A. except } \\
\text { for Colombia } \\
\text { and Venezuela }\end{array}$ & $6 \mathrm{~h}$ & 7.0 & All & V. Good \\
\hline Alt. 10 & 470.000 & Brazil & L.A. & $8 \mathrm{~h}$ & 6.7 & All & Regular \\
\hline
\end{tabular}

Table 4 - Maximum and minimum values of the alternatives in relation to the attributes.

\begin{tabular}{|c|c|c|c|c|c|c|c|c|c|c|c|c|c|c|}
\hline \multirow{3}{*}{ Alternatives } & \multicolumn{14}{|c|}{ Criteria } \\
\hline & \multicolumn{2}{|c|}{$\begin{array}{c}\text { Anual } \\
\text { cost }\end{array}$} & \multicolumn{2}{|c|}{ Capillarity } & \multicolumn{2}{|c|}{$\begin{array}{c}\text { Strategic } \\
\text { alignment }\end{array}$} & \multicolumn{2}{|c|}{ SLA } & \multicolumn{2}{|c|}{$\begin{array}{c}\text { Quality of } \\
\text { service }\end{array}$} & \multicolumn{2}{|c|}{$\begin{array}{l}\text { Technical } \\
\text { resources }\end{array}$} & \multicolumn{2}{|c|}{ Mgt } \\
\hline & $\min$ & $\max$ & $\min$ & $\max$ & $\min$ & $\max$ & $\min$ & $\max$ & $\min$ & $\max$ & $\min$ & $\max$ & $\min$ & $\max$ \\
\hline Alt. 1 & 0.9 & 0.9 & 1.0 & 1.0 & 0.5 & 0.5 & 1.0 & 1.0 & 0.7 & 0.8 & 1.0 & 1.0 & 0.7 & 1.0 \\
\hline Alt. 2 & 0.3 & 0.3 & 0.5 & 0.7 & 1.0 & 1.0 & 1.0 & 1.0 & 0.6 & 0.7 & 1.0 & 1.0 & 0.5 & 0.7 \\
\hline Alt. 3 & 0.6 & 0.6 & 0.5 & 0.7 & 0.7 & 0.8 & 0.8 & 0.8 & 0.6 & 0.7 & 1.0 & 1.0 & 0.7 & 1.0 \\
\hline Alt. 5 & 1.0 & 1.0 & 1.0 & 1.0 & 0.5 & 0.5 & 1.0 & 1.0 & 0.5 & 0.7 & 0.6 & 0.6 & 0.1 & 0.4 \\
\hline Alt. 6 & 0.5 & 0.5 & 1.0 & 1.0 & 0.5 & 0.5 & 0.5 & 0.5 & 0.6 & 0.6 & 1.0 & 1.0 & 0.5 & 0.7 \\
\hline Alt. 8 & 0.8 & 0.8 & 0.5 & 0.7 & 0.7 & 0.8 & 0.0 & 0.0 & 0.8 & 0.9 & 0.6 & 0.6 & 0.7 & 1.0 \\
\hline Alt. 9 & 0.5 & 0.5 & 0.5 & 0.7 & 0.7 & 0.8 & 1.0 & 1.0 & 0.7 & 0.8 & 1.0 & 1.0 & 0.7 & 1.0 \\
\hline Alt. 10 & 0.0 & 0.0 & 1.0 & 1.0 & 1.0 & 1.0 & 0.8 & 0.8 & 0.6 & 0.7 & 1.0 & 1.0 & 0.1 & 0.4 \\
\hline
\end{tabular}

Figure 6 presents the dominance existing between the alternatives according to the data given in Figure 5. The dominant alternative appears on the left side and the dominated alternative on the right.

It becomes clear that the alternatives 1 and 9 are the only ones not dominated. This demonstrates that the reference attribute was chosen well, providing a high percentage of dominated alternatives. However, it was still necessary to define whether alternative 1 or alternative 9 should be recommended.

Returning to Table 3, and evaluating the differences between these alternatives, it can be seen that alternative 1 is better in the attribute "Cost" $(400,000 \times 430,000)$, and that alternative 9 is 


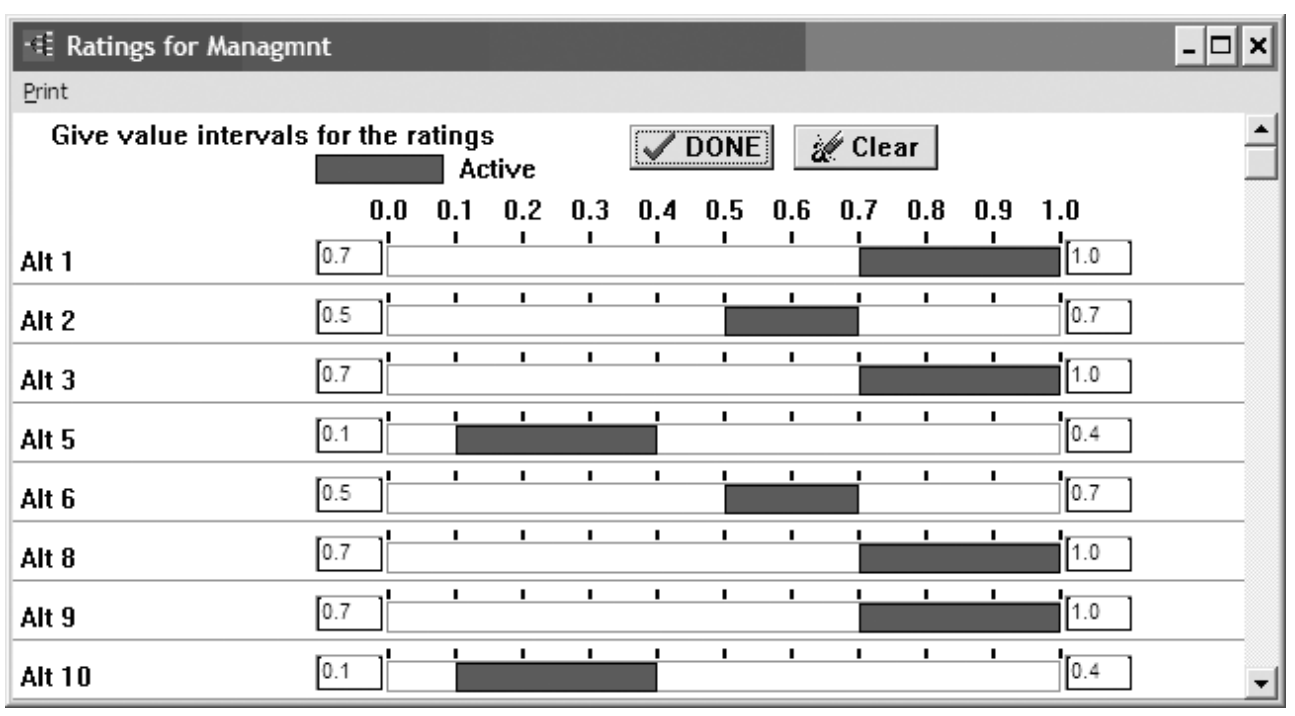

Figure 4 - Scoring of the alternatives in relation to the attribute "Management".

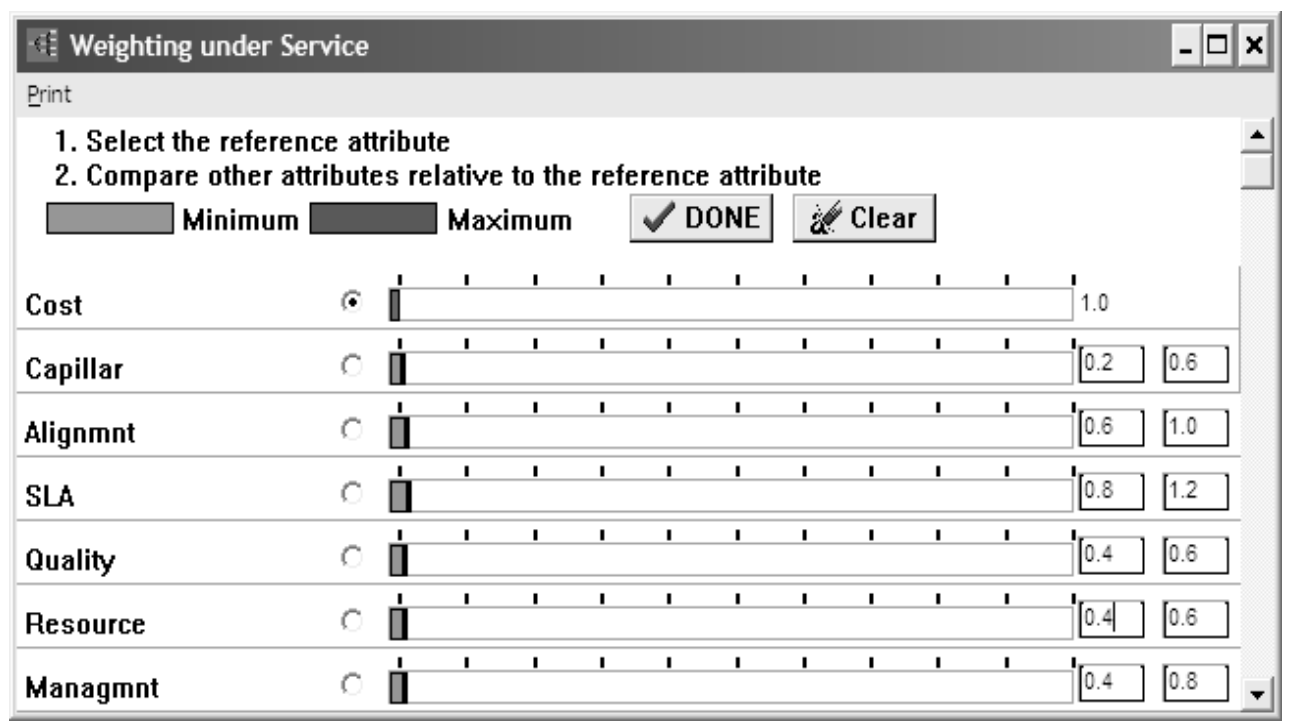

Figure 5 - Weights captured by the WINPRE software.

best in the attribute "Strategic Alignment" (Latin America apart from Colombia and Venezuela $\times$ Brazil). These attributes, in conjunction with the attribute "SLA" are the ones which carry the most weight among all the attributes evaluated.

The question which must be answered is: Is it worth paying 30,000 reais more per year to have strategic alignment including the main countries (Brazil, Mexico, Argentina and Chile)? On the other hand, it can also be asked: Is it worth paying 30,000 reais less per year to have a solution which only serves Brazil? 


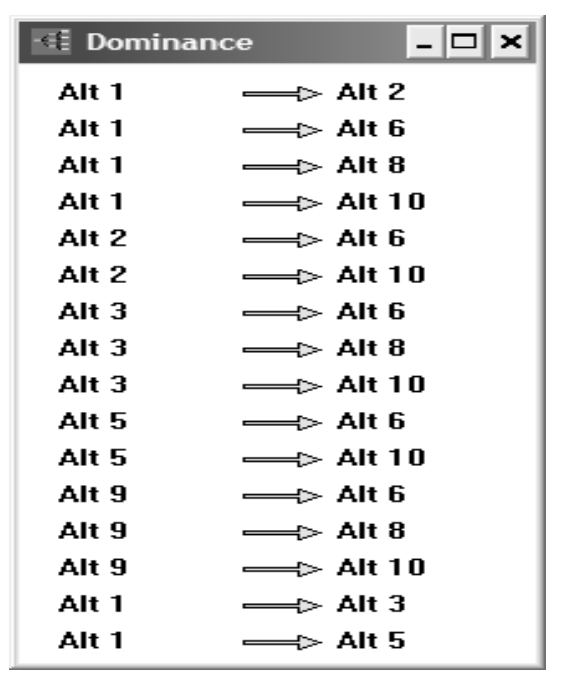

Figure 6 - Dominance captured by the software WINPRE.

Evaluating the description of the problem, and the objectives which must be reached with this project, and considering that a sensitivity analysis will still be made, at this moment alternative 9 is recommended based on the following arguments: i) Alternative 9, in spite of having a higher cost than alternative 1 , still reduces the current cost by 70,000 reais, which corresponds to approximately 14\%; and ii) The cost difference to alternative 1 can be achieved later, with a renegotiation including the other countries in Latin America, considered in the alternative 9 solution.

\subsubsection{Sensitivity analysis}

In this analysis, the result encountered in the dominance analysis stage shown in figure 19 will be compared to the result of a new analysis which will rank the alternatives by the aggregate value, calculated using the minimum, maximum and central values respectively, based on the formula number " 1 ".

The minimum aggregate value will be calculated using the minimum values defined in the intervals of the values of the weights and the values of the alternatives in relation to the weights.

The maximum aggregated value will be calculated using the maximum values defined in the intervals of the values of the weights and the values of the alternatives in relation to the weights.

The central aggregated value will be calculated using the mathematical average of the maximum and minimum values defined in the intervals of the values of the weights and the values of the alternatives in relation to the weights respectively.

Table 5 shows the aggregate values calculated according to the scoring of the alternatives in relation to the attributes presented in Table 4, and the weights given using the reference attribute "Cost", as shown in Figure 5. 
Table 5 - Classification considering the minimum, maximum and central values.

\begin{tabular}{|c|c|c|c|c|c|c|}
\hline \multirow{2}{*}{ Alternatives } & \multicolumn{2}{|c|}{ Minimum } & \multicolumn{2}{c|}{ Maximum } & \multicolumn{2}{c|}{ Central } \\
\cline { 2 - 7 } & $\begin{array}{c}\text { Aggregate } \\
\text { Value }\end{array}$ & Classification & $\begin{array}{c}\text { Aggregate } \\
\text { Value }\end{array}$ & Classification & $\begin{array}{c}\text { Aggregate } \\
\text { Value }\end{array}$ & Classification \\
\hline Alt. 1 & 3.14 & 1 & 14.88 & 1 & 9.01 & 1 \\
Alt. 2 & 2.58 & 5 & 13.53 & 3 & 8.06 & 4 \\
Alt. 3 & 2.66 & 4 & 13.48 & 4 & 8.07 & 3 \\
Alt. 5 & 2.76 & 2 & 11.12 & 8 & 6.94 & 7 \\
Alt. 6 & 2.22 & 6 & 12.26 & 6 & 7.24 & 6 \\
Alt. 8 & 2.10 & 8 & 11.67 & 7 & 6.89 & 8 \\
Alt. 9 & 2.76 & 2 & 14.22 & 2 & 8.49 & 2 \\
Alt. 10 & 2.13 & 7 & 13.18 & 5 & 7.65 & 5 \\
\hline
\end{tabular}

The result presented in Table 5, shows that the alternatives 1 and 9 are always classified as first and second respectively.

The sensitivity analysis confirms that the alternatives 1 and 9 are the best alternatives. As a consequence, the choice of alternative 9 will be maintained as the alternative recommended to provide the printing service according to the criteria defined.

\section{CONCLUSION}

The use of a multicriteria decision aiding method was shown to be useful in this case study, as it generated well-founded, transparent recommendations in an organised way, capable of keeping the discussions on technical criteria, not permitting the process to get lost in irrelevant discussions with little objectivity in relation to the decision process in question. The MAUT method has indeed shown to be a method which is simple enough to be understood and used by managers, and, at the same time, one which provides results which are easy to defend, principally when it involves various decision makers from the company.

The use of the INTERVAL SMART/SWING WEIGHTING method contributed towards covering any imprecision in the judgements, leaving the decision makers in a more comfortable position. It also allows the intervals to be revised throughout the study to represent a reality which had not been perceived before. However, the fact that the decision makers feel more comfortable may generate a failure in the search for more complete information, in other words, if the decision maker can judge via an interval, this judgement does not require such precision in the information. It is possible to get around this problem in the sensitivity analysis phase, narrowing the intervals through the search for more complete information.

The choice of the reference attribute was also shown to be fundamental, confirming that the choice of the most precise attribute is most recommended (Mutajoki, Hamalainen \& Salo, 2005). The choice of the attribute "Cost" generated an analysis of dominance where only two dominant alternatives remained. 
The current market requires decisions to be made in a quick and precise way, and consequently, with incomplete information. This scenario contributed to generating uncertainty in the analysis of the criteria and alternatives. The use of these methods permits interactivity during the whole of the decision making process, keeping the discussions focused on the problem in question, and presenting the solution in a transparent way which is easy for the participants to understand. In this way it strongly minimises the possibility of financial loss through the choice of an inappropriate alternative. As a result of the process being documented at all stages, it can be used for consultation in other similar processes.

\section{ACKNOWLEDGEMENTS}

The authors are grateful to the referees for their insightful comments on the first version of this paper. This work was partially supported by CNPq throught Research Projects No. 310603/ 2009-9 and 502711/2009-4.

\section{REFERENCES}

[1] Bana e Costa CA. 1990. Readings in Multiple Criteria Decision Aid. Berlin: Springer Verlag.

[2] Belton V \& Stewart TJ. 2002. Multiple criteria decision analysis: an integrated approach. Boston: Kluwer Academic Press.

[3] Bogetoft P \& Pruzan P. 1991. Planning with Multiple Criteria: Investigation, Communication, Choice. Amsterdam: Copenhagen Business School Press.

[4] Clemen RT \& Reilly T. 2001. Making Hard Decisions with Decisions Tools. $2^{\text {nd }}$ ed. Pacific Grove: Duxbury.

[5] EdWARdS W. 1971. Social utilities. Engineering Economist, Summer Symposium Series, 6: 119-129.

[6] FishbuRn P. 1970. Utility Theory for Decision Making. New York: John Wiley \& Sons.

[7] Gomes lfma, Araya MCG \& Carignano C. 2004. Tomada de decisões em cenários complexos: introdução aos métodos discretos do apoio multicritério à decisão. São Paulo: Pioneira Thomson Learning.

[8] Gomes LFAM \& RANGel LAD. 2009. Determining the utility functions of criteria used in the evaluation of real estate. International Journal of Production Economics, 117: 420-426.

[9] Keeney RL. 1982. Decision Analysis: An Overview. Operations Research, 30: 803-838.

[10] Keeney RL \& Raiffa H. 1976. Decisions with Multiple Objectives: Preferences and Value Tradeoffs. New York: John Wiley \& Sons.

[11] Meirelles CLA \& Gomes LFAM. 2009. O apoio multicritério à decisão como instrumento de gestão do conhecimento: uma aplicação à indústria de refino de petróleo. Pesquisa Operacional, 29(2): 451-470.

[12] Miller GA. 1956. The magical number seven, plus or minus two: Some limits on our capacity for processing information. Psychological Review, 101(2): 343-352. 
[13] Mustajoki J, Hamalainen RP \& Salo A. 2005. Decision support by interval SMART/SWING - Incorporating imprecision in the SMART and SWING methods. Decision Sciences, 36(2): 317 339.

[14] Poyhonen M \& Hamalainen RP. 2001. On the convergence of multiattribute weighting methods. European Journal Operational Research, 129: 569-585.

[15] Rangel LAD \& Gomes LFAM. 2009. Emprego dos métodos Utilité Additive e Utilité Additive CRiteria na avaliação de imóveis: um estudo de caso. Gestão \& Produção, 16(2): 222-231.

[16] Rosenhead J \& Mingers J. (Eds.). 2008. Rational Analysis for a Problematic World Revisited Problem Structuring Methods for Complexity, Uncertainty and Conflict. Chichester: John Wiley \& Sons.

[17] RoY B. 1985. Méthodologie Multicritère d'Aide à la Décision. Paris: Economica.

[18] Roy B \& Bouyssou D. 1993. Aide Multicritère à la Decision. Paris: Economica.

[19] SAATY TL. 1994. Fundamentals of Decision Making and Priority Theory with the Analytic Hierarchy Process. Pittsburgh: RWS Publications.

[20] Salo A \& Hamalainen RP. 2001. Preference Ratios in Multiattribute Evaluation (PRIME) Elicitation and Decision Procedures under Incomplete Information. IEEE Transactions on Systems, Man, and Cybernetics Journal, 31: 533-545.

[21] Von Winterfeldt D \& Edwards W. 1986. Decision Analysis and Behavioural Research. New York: Cambridge University Press.

[22] Weber M. 1987. Decision making with incomplete information. European Journal of Operational Research, 28: 44-57.

[23] Weber M \& Borcherding K. 1993. Behavioral Influences on Weight Judgements in Multiatribute Decision Making. European Journal of Operational Research, 67: 1-12.

[24] WINPRE. 2009. Decision analysis with imprecise ratio statements - preference programming, PAIRS. Disponível em $<$ http://www.sal.hut.fi/Downloadables/winpre.html $>$. Access in: July $7^{\text {th }}$. 